\title{
Evaluasi Pemakaian Steam Cleaner Untuk Pembersihan Candi Borobudur
}

\author{
Oleh : \\ Iskandar Mulia Siregar, S.Si \\ Balai Konservasi Peninggalan Borobudur
}

\section{Pendahuluan}

Steam cleaner telah dipergunakan sejak awal tahun 80an untuk membersihkan batu-batu Candi Borobudur. Walaupun dengan batasan-batasan tertentu, pemakaian Steam cleaner sangat membantu usaha pelestarian Candi Borobudur khususnya untuk membersihkan permukaan batu dari organisme perusak dan pelapuk. Namun demikian walaupun telah dipakai lebih dari 20 tahun, sampai saat ini belum pernah dilakukan evaluasi mengenai efektivitas dan dampak negatif dari pemakaian alat Steam cleaner tersebut terhadap batubatu Candi Borobudur. Hal ini lain halnya dengan pemakaian sikat ijuk, sikat nilon, sapu lidi yang telah pernah dilakukan kajian/studi mengenai efektivitas dan dampak negatifnya terhadap kelestarian batu-batu Candi Borobudur baik metode kering maupun dengan metode basah.

Penelitian ini dilakukan dengan menguji pemakaian Steam cleaner terhadap pembersihan batubatu Candi Borobudur, yaitu pada pagar langkan dan koleksi batu lepas yang terdapat di Museum Karmawibahgga. Pengujian dilakukan dengan menerapkan beberapa variabel jarak, tekanan, dan temperatur air terhadap jenis batu porous, medium dan kompak. Parameter yang diamati adalah tingkat kebersihan batu, kerontokan batu dan pertumbuhan kembali organisme. Tujuan dari pengujian ini adalah untuk mengevaluasi efektivitas pemakaian Steam cleaner dan dampaknya terhadap batu
Candi Borobudur.

$\mathrm{Has}$ il penelitian menunjukkan Steam cleaner dapat dipakai untuk membersihkan material benda cagar budaya yang terbuat dari batu andesit seperti yang terdapat di Candi Borobudur. Pemakaian Steam cleaner ini harus dilakukan secara selektif dengan metode yang tepat, yaitu hanya diterapkan pada batu polos dengan jarak pembersihan $25 \mathrm{~cm}$ dan tekanan 100 Bar.

Seiram a dengan perkembangan zaman dan teknologi, sejak awal tahun 80-an Steam cleaner mulai di pakai di Candi Borobudur sebagai alat bantu untuk membersihkan batu-batu candi. Di samping itu sikat ijuk, sikat nilon, dan sapu lidi tetap dipergunakan. Pemakaian Steam cleaner sangat membantu petugas di lapangan karena dalam waktu yang relatif singkat dapat menyelesaikan pekerjaan yang seharusnya memakan waktu yang cukup lama jika harus dikerjakan oleh manusia. Akan tetapi tenaga manusia (karyawan) tetap sangat diperlukan, di samping sebagai operator mesin tersebut, ada tempat-tempat tertentu yang tidak dapat dijangkau atau batu-batu yang tidak diizinkan dibersihkan menggunakan Steam cleaner. Batu yang boleh dibersihkan menggunakan Steam cleaner hanyalah batu-batu polos sedangkan batu berrelief atau batu yang kelihatan sudah rapuh tidak diizikan sama sekali menggunakan. Steam cleaner.

Candi Borobudur mulai dibangun oleh Dynasti Syailendra abad ke-8 pada masa kepemimpinan Raja Samaratungga. Candi Borobudur yang dibangun di atas bukit yang diurug dan diratakan serta hampir seluruhnya terbuat dari batuan beku yaitu jenis batu andesit. Jumlah batu Candi Borobudur kurang lebih 2 juta blok atau sekitar $55.000 \mathrm{~m}^{3}$. Permukaan batu Candi Borobudur yang tampak dan yang harus selalu dirawat dan dipelihara setiap hari ada sekitar $15.983 \mathrm{~m}^{2}$. Dengan demikian batu-batu asli Candi Borobudur telah berada di alam terbuka lebih dari 1.000 tahun. Dapat dibayangkan batu-dalam hal ini andesit-yang telah terpasang cukup lama di alam terbuka dengan cuaca yang selalu berubah-ubah akan mengalami penurunan kualitas karena terjadinya degradasi mineralmineral penyusunnya. Pengaruh panas dan dingin tidak bisa dihindari akan mempengaruhi kondisi batu yang membuat batu semakin lama akan makin rapuh.

Batu dengan kondisi seperti itulah yang akan diuji coba dibersihkan dengan Steam cleaner dalam studi/kajian ini. Di samping kita mengharapkan pembersihan yang optimal kita juga harus mempertimbangkan dampak negatif terhadap batu, misalnya kerontokan batu sehingga harapan agar Candi Borobudur dapat tetap lestari untuk 1.000 tahun yang akan datang dapat terwujud sesuai dengan harapan Presiden Republik Indonesia saat itu, Soeharto yang disampaikan pada amanatnya saat peresmian pasca pemugaran Candi Borobudur tanggal 23 Februari 1983.

Tujuan Dan Menfaat Penelitian 
Tujuan penelitian adalah untuk mengevaluasi efektivitas dan dampak pemakaian Steam cleaner terhadap kelestarian batu-batu Candi Borobudur, sehingga dapat diambil kesimpulan apakah alat tersebut dapat atau tidak dapat dipakai untuk membersihkan gulma pada batu-batu Candi Borobudur. Studi ini dilaksanakan dengan melakukan serangkaian eksperimen dengan berbagai macam variasi dan variabel dalam aktifitas pembersihan batu-batu Candi Borobudur dengan Steam cleaner:

Kajian ini diharapkan dapat memberi gambaran tentang efetifitas dan dampak penggunaan Steam cleaner pada pembersihan material benda cagar budaya. Dengan demikian dapat dijadikan sebagai acuan penggunaan Steam cleaner pada perawatan benda cagar budaya di Candi Borobudur khususnya dan umumnya benda cagar budaya lainnya yang berbahan batu andesit di seluruh Indonesia.

\section{Metode Penelitian}

Penelitian dimulai dengan survai untuk mencari dan menentukan sampel batu yang paling sesuai dengan tujuan penelitian. Batu tersebut dipilih berdasarkan klasifikasi porus, medium dan kompak serta harus ditumbuhi organisme dengan populasi yang cukup banyak. Setelah ditemukan batu tersebut ditempatkan pada lokasi yang agak terpisah dari batu-batu lainnya untuk memudahkan pengamatan setelah dibersihkan. Setiap batu yang telah dipilih untuk pengujian dicatat ukurannya. Sementara itu untuk eksperimen yang dilakukan pada batu Candi Borobudur setelah ditentukan lokasi yang sesuai untuk penelitian, lokasi tersebut ditandai dan dicatat tanpa memperdulikan $b$ a $t$ u a $n$ berdasarakan $\mathrm{klas}$ if i ka s i porositasnya Akan tetapi diaplikasikan berdasarkan luas permukaan batu $\left(\mathrm{m}^{2}\right)$. Pada Candi Borobudur lokasi

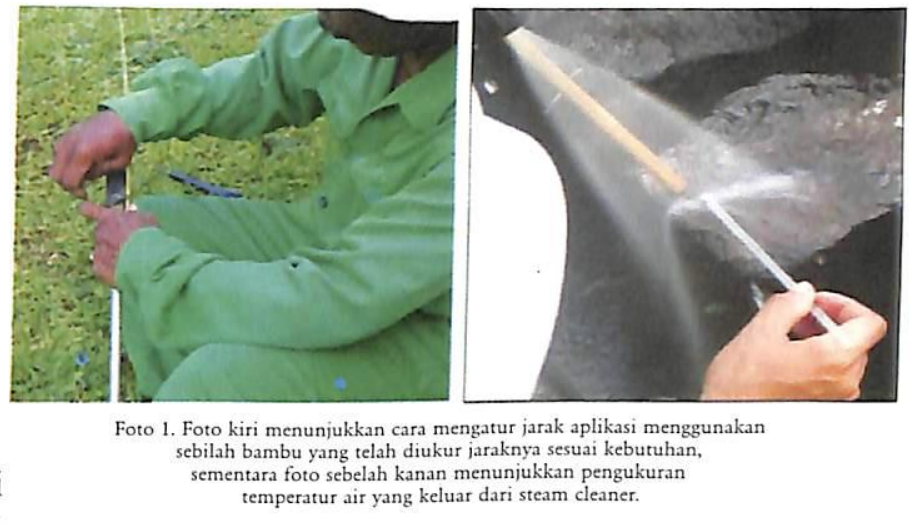
yang dipakai untuk pengujian ini berada di dinding undag sisi Utara bidang a serta pada batu pagar langkan sisi Utara tingkat I tampak dalam bidang d, e, f, dan h. Sementara itu untuk mengetahui dampak pemakaian Steam cleaner terhadap patina, dilakukan aplikasi pada arca Budha yang juga terdapat d i hala man Muse um Karmawibhangga

Steam cleaner adalah alat pembersih dengan metode semprot dimana temperatur dan tekanan air yang dikeluarkan dapat diatur sesuai kebutuhan pemakai, yang saat ini umum dipakai untuk membersihkan gedung, lantai, kendaraan dan lainlain. Di pasaran alat semacam ini tersedia dalam berbagai merk, spesifikasi dan kualitas sehingga setiap orang dapat memilih sesuai dengan kebutuhannya masingmasing dengan memperhatikan kebutuhan dan objek yang akan dibersihkan. Di Candi Borobudur telah pernah digunakan Steam cleaner dari berbagai merk dan spesifikasi teknis yang berbeda.

Dalam penelitian ini variabel yang akan diuji adalah jarak pembersihan (cm), tekanan air (bar), temperatur air ('C), dan waktu (menit). Sedangkan parameter yang akan diamati adalah: kebersihan batu (\%), Kerontokan batu (gram $\left./ \mathrm{cm}^{2}\right)$, pertumbuhan kembali organisme (hari), dampak pemakaian alat terhadap patina batu.
Untuk menguji semua variabel dan parameter itu pada prakteknya dilakukan dengan caracara yang sederhana. Tekanan dapat langsung diatur dari alat, temperatur pada air yang keluar dari nose Steam cleaner pada jarak tertentu sesuai kebutuhan. Untuk menentukan jarak aplikasi dilakukan dengan mengikatkan sebilah bambu pada diinginkan.

\section{Hasil Dan Pembahasan}

Beberapa catatan penting yang perlu dijelaskan sebelum membahas hasil dari penelitian adalah tentang temperatur dan tekanan. Temperatur rata-rata akan turun sekitar 3,0 - 3,5\% per meter. Dengan demikian jika digunakan selang dengan panjang 10 meter maka temperatur akan turun sekitar $30-35 \%$. Seperti yang telah diukur, pada saat diatur pada temperatur $100^{\circ} \mathrm{C}$ ternyata pada nose (ujung) gun Steam cleaner temperatur air adalah $65^{\circ} \mathrm{C}$ dan pada jarak $25 \mathrm{~cm}$ berkurang menjadi $60^{\circ} \mathrm{C}$ serta pada jarak $35 \mathrm{~cm}$ temperatur menjadi $55^{\circ} \mathrm{C}$. Demikian juga halnya dengan tekanan yang ditunjukkan pada manometer alat merupakan tekanan yang keluar dari nose (ujung) gun alat Steam deaner tersebut sedangkan tekanan yang menerpa batu berkurang sekitar 20\% juga. Jadi diukur langsung dengan termometer ujung gun sesuai jarak yang 
tekanan yang ditunjukkan oleh alat dalam satuan Bar akan berkurang pada saat mengenai batu-batu Candi Borobudur. Informasi ini akan sangat berguna dan diperlukan dalam membahas hasil dan dampak negatif penggunaan Steam cleaner terhadap batu-batu Candi Borobudur.

Dari eksperimen yang telah dilakukan akan dibahas dan dievaluasi tingkat kebersihan, kerontokan batu, pertumbuhan kembali organisme setelah dibersihkan menggunakan Steam cleaner. Dari uraian itu akan dapat disimpulkan apakah Steam cleaner layak digunakan serta untuk menentukan metode dan jarak yang tepat untuk membersihkan benda cagar budaya yang terbuat batu andesit seperti Candi Borobudur.

\section{Parameter yang Diamati}

Tingkat kebersihan batu setelah dibersihkan dengan alat Steam cleaner diamati secara visual beberapa saat setelah batu dibersihkan bila perlu dengan bantuan kaca pembesar (loupe). Tingkat kebersihan dinyatakan dalam persen (\%) dengan membandingkan batu sebelum dan setelah dibersihkan.

torium lalun ditimbang jumlahnya. Butiran lain yang menempel pada batu dan sisa-sisa organisme ikut mempengaruhi objektivitas jumlah kerontokan walau $s$ u d a $h$ diminimalisasi dengan berbagai cara.

Paramater lain yang cukup penting adalah

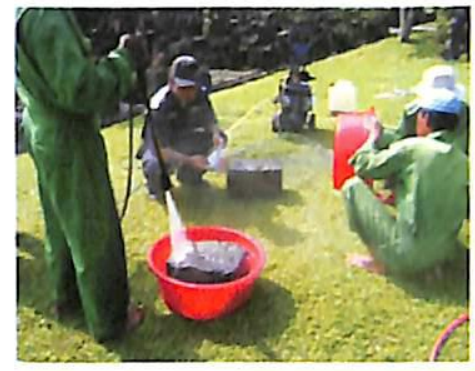

Foto 3. Batu lepas sedang dibersihkan di dalam baskom sebagai penampung kerontokan batu dan dicatat ukurannya.

pertumbuhan kembali organisme (hari) pada batu stelah dibersihkan dengan steam clenaer. Parameter ini menjadi salah satu indikator efektivitas alat tersebut untuk membersihkan batu-batu Candi Borobudur. Berdasarkan penelitian sebelumnya organisme akan tumbuh kembali 5 - 25 hari setelah dibersihkan dengan sikat ijuk (Sukrodeni dkk., 2000).

\section{Aplikasi pada Batu-batu Lepas}

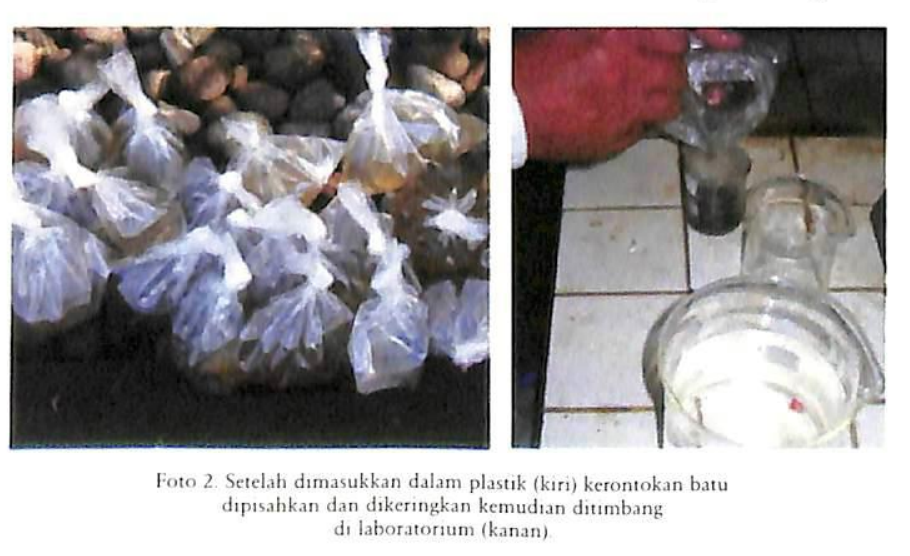

1. $\mathrm{T}$ ing k a t Kebersihan

Dari pengujian di lapangan ternyata untuk semua jenis batu (kompak, medium, dan porous ) pembersihan menggunakan Steam cleaner baik dengan air Kerontokan batu (gram) diukur dengan mengumpulkan biasa $\left( \pm 25^{\prime \prime} \mathrm{C}\right)$ maupun dengan panas $\left( \pm 100^{\prime \prime} \mathrm{C}\right)$ tingkat kebersihan batu ratarata di atas $80 \%$.

Dengan tekanan sekitar 125 Bar dan air biasa ternyata hampir semua organisme yang tumbuh pada batu dapat dibersihkan baik untuk jenis batu kompak, medium, maupun batu porous. Tingkat kebersihan ini hampir sama untuk jarak pembersihan 25 $\mathrm{cm}$ dan 35 serta dengan waktu 30 dan 60 detik. Sementara itu dengan tekanan sekitar 100 Bar dan aipr panas $\left(100^{\circ} \mathrm{C}\right)$ tingkat kebersihan semua jenis batu sedikit lebih rendah daripada yang dibersihkan dengan tekanan 125 bar untuk masing-masing jarak $25 \mathrm{~cm}$ dan $35 \mathrm{~cm}$ baik untuk waktu 30 maupun 60 detik.

2. Kerontokan batu

Dari ekperimen ternyata secara umum kerontokan batu akibat pembersihan batu dengan Steam cleaner lebih 


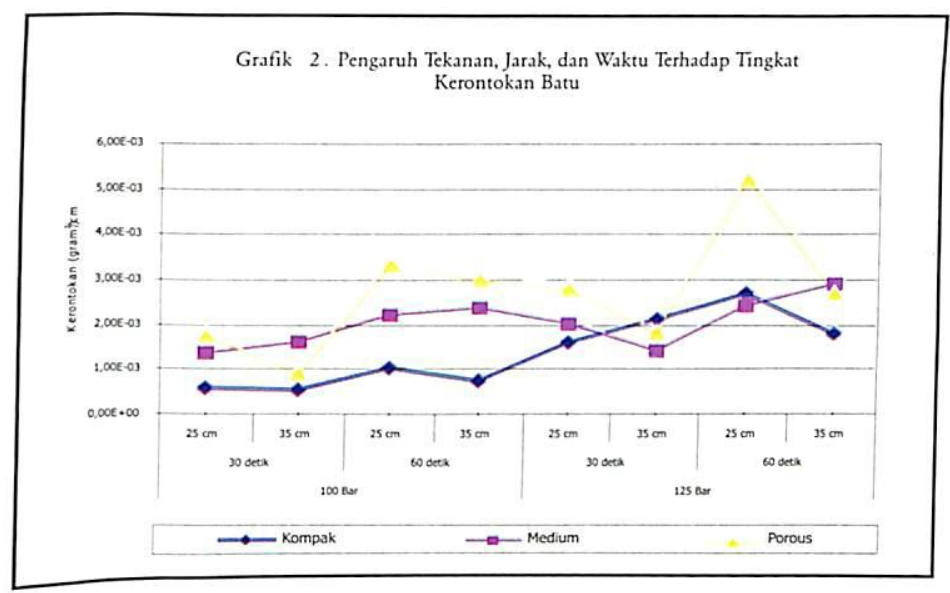

besar daripada kerontokan batu yang disebabkan oleh pembersihan secara mekanis menggunakan sikat ijuk dan sapu lidi baik secara basah maupun kering.

Dari Grafik 2. terlihat kerontokan batu terbesar terjadi pada penyemprotan dengan jarak $25 \mathrm{~cm}$ dengan waktu 60 detik baik untuk air biasa maupun dengan air panas. Secara umum kerontokan terbesar terjadi pada batu-batu porous yang secara teoritis juga ikatan mineral pada bagian kulit batu telah jauh berkurang atau mengalami degradasi. Akan tetapi ada beberapa pengecualian, misalnya penyemprotan dengan air biasa dengan tekanan 100 Bar, jarak $35 \mathrm{~cm}$, dan waktu 30 detik, selanjutnya pada tekanan 125 Bar, jarak $35 \mathrm{~cm}$, dan waktu 30 detik serta pada pengujian dengan tekanan 125 Bar dan pembersihan selama 60 baik untuk jarak 25 $\mathrm{cm}$ maupun $35 \mathrm{~cm}$. Dari kecenderungan secara umum dapat disimpulkan bahwa $\mathrm{p}$ e $\mathrm{n}$ y $\mathrm{i}$ m p a $\mathrm{n}$ a $\mathrm{n}$ penyimpangan ini terjadi karena kesalahan manusia baik karena kesalahan pengambilan sampel di lapangan maupun karena

$y$ a $n$ g dominan mempen kerontok an batu a d a l a h ja r a k, w a k t u d a n tekanan.

Pertumb

u h a n kesalahan pemisaha n antara kerontoka n batu dan sis a-sis a organisme di laboratorium. A $\mathrm{k}$ a $\mathrm{n}$ t e t a p i $\mathrm{s}$ e c a r a

keseluruhan hasil pengujian ini cukup representatif untuk men y t a k n bahwa penyemprotan dengan tekanan 125 pada jarak $25 \mathrm{~cm}$ selama 60 detik memberikan dampak negatif berupa kerontakan batu paling besar. Pada kondisi ini rata-rata kerontokan batu porous untuk tekanan 100 Bar adalah $3,44 \times 10-3 \mathrm{gram} / \mathrm{cm}^{2}$ dan $5,33 \times 10-3 \mathrm{gram} / \mathrm{cm}^{2}$ untuk Steam cleaner dengan tekanan 125 Bar atau bertambah sekitar 55\%. Dari grafik tersebut juga terlihat bahwa temperatur batu tidak terlalu berpengaruh terhadap besar kecilnya kerontokan batu, $\mathrm{g}$ a r u h i

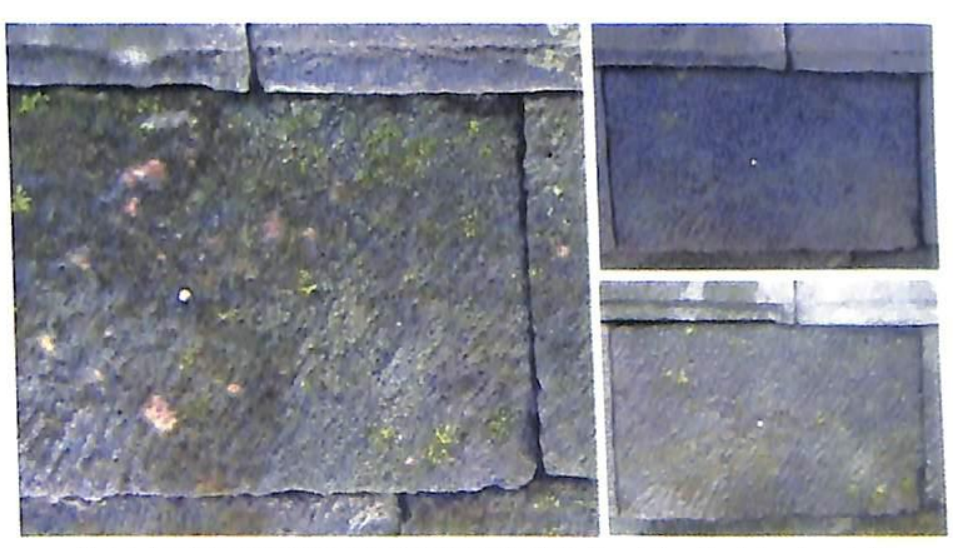

Foto 4. Searah jarum jam batu pagar langkan tingkat I sisı Utara bidang $\mathrm{h}$ sebelum dan setelah dibersihkan serta setelah ditumbuhi lumut kembali pada hari ke delapan

kembali organisme

Dari hasil eksperimen terhadap batu-batu lepas yang berada di halaman Museum
Karmawibhangga, sampai minggu ke-3 setelah dibersihkan dengan Steam cleaner belum ada tanda-tanda akan ditumbuhi organisme. Batu-batu setelah dibersihkan ditempatkan pada lokasi yang tidak terkena langsung dengan tanah, sehingga tidak terjadi proses kapilarisasi. Akan tetapi setelah dibersihkan faktor memacu pertumbuhan organisme lainnya tetap ada karena batubatu tersebut dibiarkan berada di halaman terbuka dan tetap tersiram air hujan yang sering turun setelah percobaan dilaksanakan.

\section{Aplikasi pada Batu Candi Borobudur (In situ)}

Lokasi yang dipakai untuk pengujian Steam cleaner secara in situ pada Candi Borobudur berada di sisi Utara yaitu pada dinding undag bidang a serta pada batu pagar langkan tingkat I tampak dalam bidang d, e, f, dan h. Pada lokasi ini jenis batu yang diuji sekaligus terdiri dari kompak, medium, dan porous.
Pada dinding undag dilakukan pembersihan dengan dengan 2 (dua) macam jarak vaitu $25 \mathrm{~cm}$ dan $35 \mathrm{~cm}$, 3 (tiga) macam tekanan yaitu 80 Bar, 
100 Bar, dan 125 Bar dengan waktu pembersihan selama 5 menit $(300$ detik) untuk setiap $1 \mathrm{~m}^{2}$ batu. Sementara untuk pengujian di pagar langkan dilakukan dengan 3 (tiga) macam jarak yaitu $15 \mathrm{~cm}, 25 \mathrm{~cm}$, dan $35 \mathrm{~cm}, 2$ (dua) macam tekanan yaitu 100 Bar dan 125 Bar dengan 2 (dua) serta dengan waktu 2,5 menit (150 detik) dan 5 menit (300 detik) untuk setiap $1 \mathrm{~m}^{2}$ batu.

\section{Tingkat kebersihan}

Hasil pengujian di lapangan menunjukkan tingkat kebersihan batu untuk tekanan 80 Bar hanya $70 \%$ - $90 \%$ sementara untuk tekanan 100 Bar dan 125 Bar tingkat kebersihan batu 85\% - $100 \%$. Hal ini terjadi untuk waktu pembersihan selama 150 detik dan 300 detik untuk setiap $1 \mathrm{~m}^{2}$ batu. Dari Grafik 3. dapat dilihat tingkat kebersihan untuk batubatu undag dan Grafik 4. untuk batu pagar langkan setelah dibersihan dengan Steam cleaner. Dari hasil ini terlihat dengan menambah lama pembersihan

\section{Kerontokan batu}

Kerontokan batu undag dan pagar langkan terbesar setelah dibersihkan menggunakan Steam cleaner adalah dengan jarak pembersihan $15 \mathrm{~cm}$ dan tekanan 125 $\mathrm{B}$ a $\mathrm{r}$ y a i t u sebesar $1,40 \mathrm{x}$ $10-3$ $\mathrm{gram} / \mathrm{cm} 2$. Sementara itu kerontokan batu terkecil terjadi untuk pembersihan dengan jarak $35 \mathrm{~cm}$ dengan tekanan 80 B a r yaitu sebesar 7,50x $10-3$ $\mathrm{gram} / \mathrm{cm}^{2}$. Grafik 3. dan Grafik 4 . menunjukkan kerontokan batuan akibat

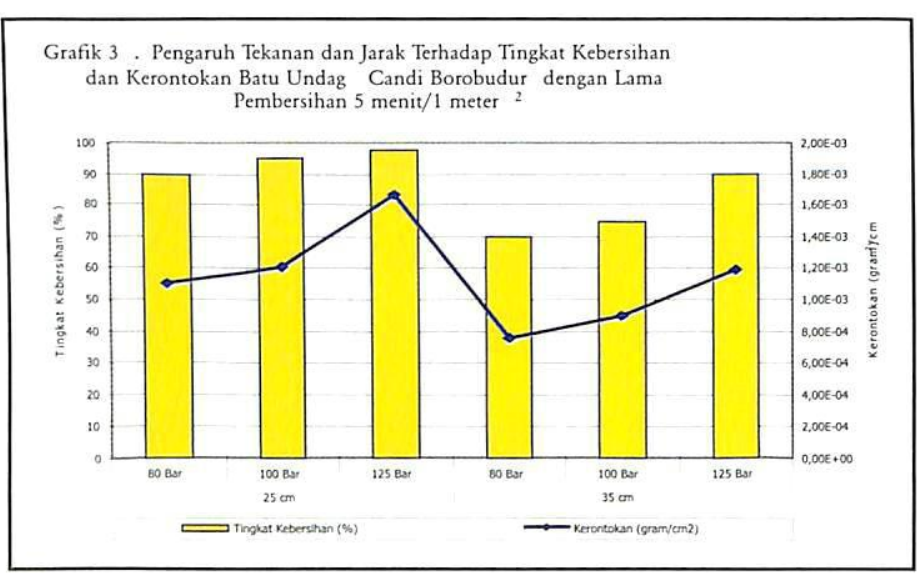

ternyata tidak menambah tingkat kebersihan secara signifikan. Dari hasil ini juga terlihat lama pembersihan yang paling baik adalah 150 detik $(2,5$ menit) untuk setiap $1 \mathrm{~m}^{2}$ permukaan batu.
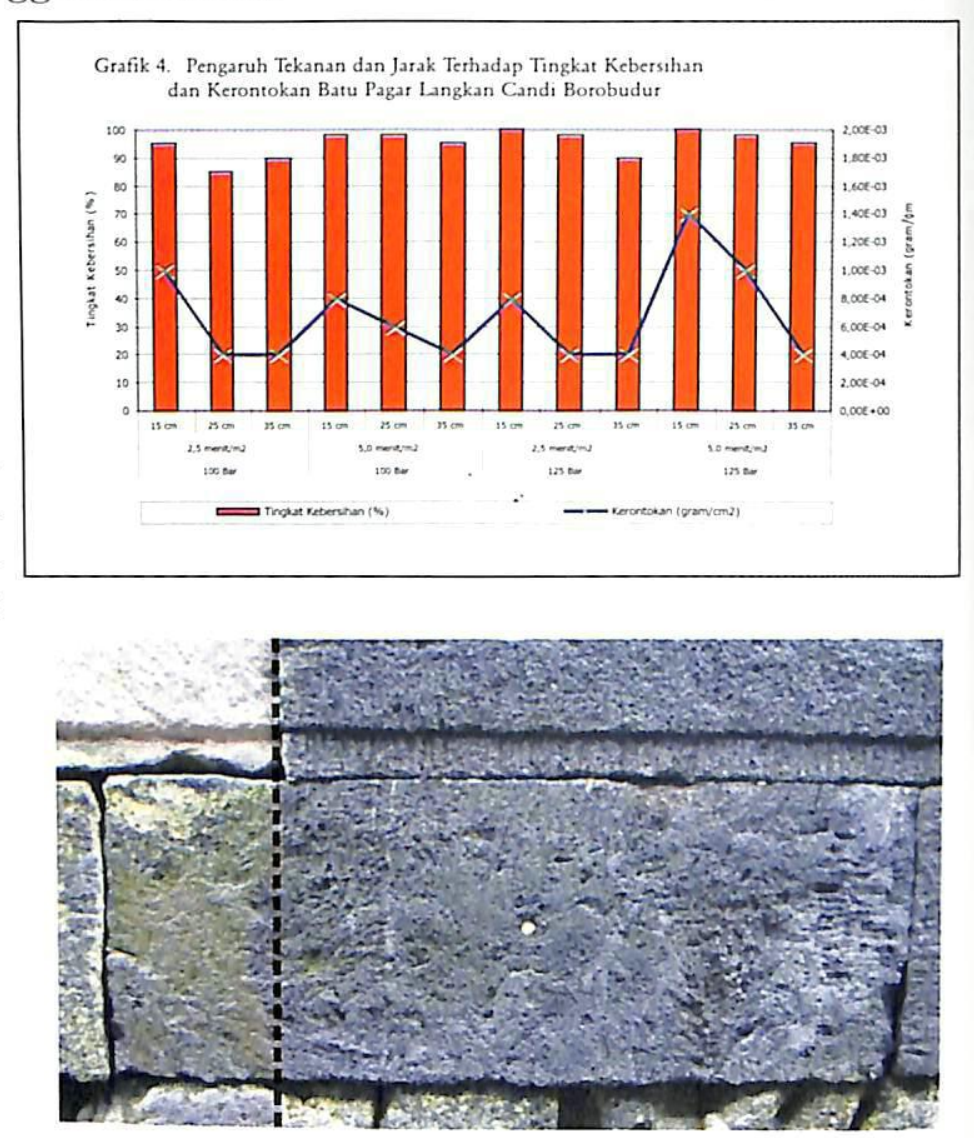

Foto. 5. Salah satu blok batu yang terkena dan tidak terkena air bertekanan tinggi yang berasal dari steam cleaner.

pembersihan dengan Steam cleaner untuk b a t u - b a t u dinding undag dan batu-batu pagar langkan $C$ a $n$ d i Borobudur. Untuk batubatu dinding undag diuji pembersihan menggunakan Steam cleaner dengan 2 jarak yang berbeda yaitu $25 \mathrm{~cm}$ dan $35 \mathrm{~cm}$ dengan 3 macam tekanan masing-masing 80 Bar, 100 Bar, dan 125 Bar. Sedangkan untuk batu-batu pagar langkan diuji pembersihan dengan 3 macam jarak, yaitu 15 dari tingkat kebersihan dan kerontokan batu ternyata pembersihan dengan jarak 25 $\mathrm{cm}$ dan tekanan $100 \mathrm{Bar}$ menghasilkan hasil terbaik.

Walaupun kerontokan batu akibat permbersihan dengan Steam cleaner untuk jarak $25 \mathrm{~cm}$ dan tekanan 100 Bar besarnya hampir 2 (dua) kali lipat jumlah kerontokan batu akibat pembersihan menggunakan sapu lidi, yaitu kerontokan terbesar untuk pembersihan secara mekanis. Pembersihan menggunakan Steam cleaner akan mengangkat seluruh debu-debu yang menempel pada batu dan kemungkinan besar masuk dan secara tidak sengaja dihitung 
sebagai kerontokan batu. Namun harus diakui secara umum kerontokan batu akibat pembersihan dengan Steam cleaner memang lebih besar daripada kerontokan batu akibat pembersihan secara mekanis baik metode basah maupun metode kering.

3. Pertumbuhan kembali organisme

Pengamatan untuk mengetahui pertumbuhan kembali organisme setelah dibersihkan dengan Steam cleaner dipantau setiap hari. Sampai minggu ketiga setelah dibersihkan dengan Steam cleaner belum ada tanda-tanda organisme mulai tumbuh pada batu dinding undag. Yang terlihat hanyalah sisa-sisa organisme yang tidak bersih atau bahkan telah mati setelah disemprot dengan air bertekanan tinggi. Tampaknya pada batu yang dibersihkan dengan air panas (uap) tingkat kematian organisme lebih tinggi daripada batu yang dibersihkan dengan air biasa. Hal ini sesuai dengan teori yang mengatakan sebagian organisme akan berhenti metabolismenya pada temperatur dan tekanan tertentu. Sementara itu dari pemantauan pada batu-batu pagar langkan tingkat I ternyata organisme khususnya lumut tampak mulai tumbuh pada hari ke-7 (tujuh) pada permukaan batu. Lumut tersebut tumbuh pada batu yang dibersihkan menggunakan Steam cleaner dengan air biasa bertekanan 100 Bar (pagar langkan tingkat I bidang h1). Sementara untuk tekanan 125 Bar lumut mulai tumbuh pada hari ke-8 (pagar langkan tingkat I bidang d1). Semua lumut tersebut terlihat tumbuh pada batu andesit yang termasuk jenis porous. Sedangkan batu-batu yang masuk jenis kompak sampai minggu ketiga belum ada tandatanda akan ditumbuhi organisme.

Secara umum terlihat batu-batu pagar langkan yang cenderung lebih lembab daripada batu-batu undag yang sama-sama berada di sisi Utara Candi Borobudur juga ikut mempengaruhi parameter pertumbuhan kembali organisme. Karena pada dasarnya kelembapan adalah salah satu faktor pemacu pertumbuhan organisme pelapuk batu. Jadi secara teoritis batu pagar langkan akan lebih cepat ditumbuhi kembali oleh organisme daripada batu-batu undag yang terkenan sinar matahari langsung.

Jika dibandingkan dengan batu yang dibersihkan secara mekanis, pertumbuhan kembali organisme pada batu yang dibersihkan menggunakan Steam cleaner ternyata lebih lama. Hal ini terjadi karena akar-akar organisme seperti lumut juga ikut tercabut jika dibersihkan dengan Steam cleaner. Di samping itu debu dan mineral lain yang menempel pada permukaan batu juga hilang sama sekali sehingga mineral pemacu pertumbuhan organisme tidak tersedia. Hal ini mudah dipahami karena karena tekanan air yang cukup tinggi dan secara merata mengenai permukaan batu mengakibatkan tercabutnya akar organisme dan hilangnya debu dan mineral.

4. Dampak Pemakaian Steam cleaner Terhadap Patina Batu

Untuk menguji dampak pemakaian Steam cleaner terhadap patina batu dilakukan pembersihan terhadap arca Buddha yang tedapat di halaman
Museum Karmawibhangga. Pembersihan dilakukan dengan 3 macam jarak yaitu $15 \mathrm{~cm}, 25$ $\mathrm{cm}$, dan $35 \mathrm{~cm}$ masing-masing dibersihkan selama 1 menit (60 detik) dengan tekanan $100 \mathrm{Bar}$ dan 125 Bar. Karena keterbatasan kedua alat yang dipergunakan, untuk tekanan 100 Bar menggunakan panas air sekitar $100^{\circ} \mathrm{C}$ sementara untuk tekanan $125 \mathrm{Bar}$ menggunakan air biasa $\left( \pm 25^{\circ} \mathrm{C}\right)$.

Dari pengujian di lapangan untuk jarak penyemprotan dengan Steam cleaner $15 \mathrm{~cm}$ terlihat adanya kecenderungan patina batu menipis yang kemungkinan akan berlanjut pada kerontokan batu. $\mathrm{Hal}$ ini terjadi baik pembersihan dengan air biasa maupun dengan air panas (steam). Sementara itu untuk jarak penyemprotan 25 $\mathrm{cm}$ dan $35 \mathrm{~cm}$ tidak terlihat kecenderungan menipisnya patina yang berarti tidak terjadi kerontokan dari arca Buddha yang menjadi objek percobaan ini. Akan tetapi perlu juga dipertimbangkan dampak pemakaian Steam cleaner terhadap patina batu dalam frekuensi yang tinggi dan dalam jangka waktu yang cukup lama. Oleh karena itu untuk melindungi patina batu yang umumnya terdapat pada arca-arca Buddha yang tidak ternilai harganya, pembersihan arca Buddha dengan Steam cleaner cukup dilakukan maksimal satu tahun sekali atau tidak dibersihkan sama sekali jika memang tidak perlu.

Sementara itu untuk tingkat kebersihan dan pertumbuhan kembali organisme tidak diamati pada percobaan ini karena arca Buddha yang menjadi objek penelitian pada bagian yang terdapat patina tidak ditumbuhi organisme pelapuk. 


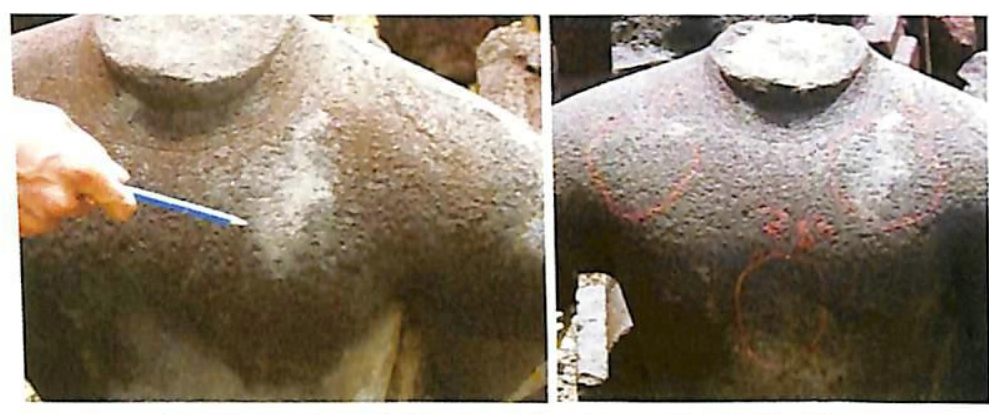

Foto 6. Patina pada arca Buddha sebelum (kanan) dan setelah (kiri) dibersihkan menggunakan steam cleaner dengan air biasa dan tekanan 125 Bar.

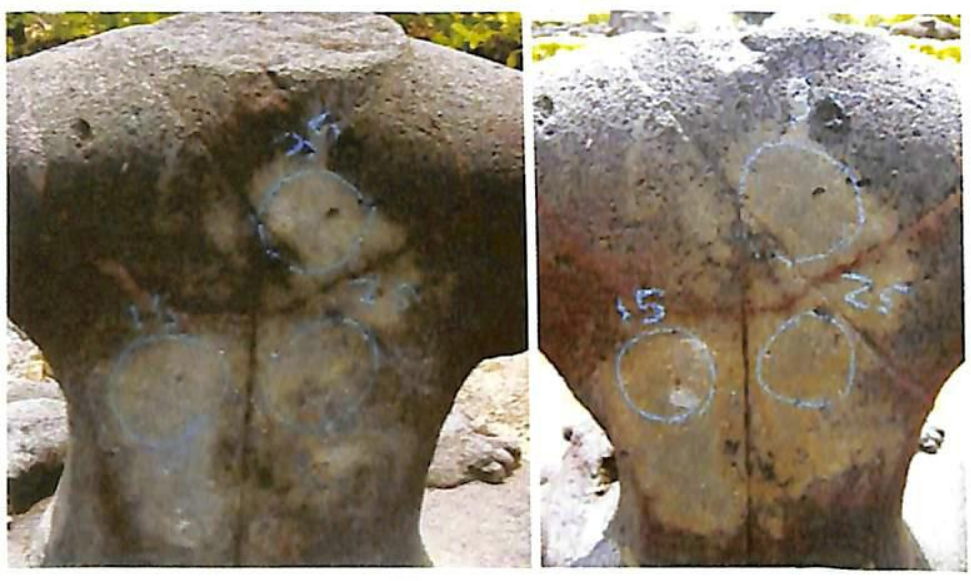

Foto 7. Patina pada arca Buddha sebelum (kanan) dan setelah (kiri) dibersihkan menggunakan steam cleaner dengan air panas (steam) dan tekanan 100 Bar.

\section{Penutup}

Kesimpulan

1. Secara umum tingkat kebersihan batu setelah dibersihkan dengan Steam cleaner lebih baik daripada pembersihan secara mekanis.

2. Pertumbuhan kembali organisme yang dibersihkan dengan Steam cleaner lebih lama daripada pembersihan secara mekanis.

3. Kerontokan batu akibat pembersihan dengan Steam cleaner lebih besar daripada kerontokan batu akibat pembersihan secara mekanis. Besarnya kerontokan batuan ini juga ditambah oleh debu-debu yang menempel pada batu.

4. Pembersihan menggunakan Steam cleaner dengan jarak $25 \mathrm{~cm}$ dan tekanan $100 \quad \mathrm{Bar}$ memberikan hasil yang paling baik jika ditinjau dari tingkat kebersihan dan kerontokan batu.
5. Steam cleaner

$h$ a $n$ y a

d a $p$ a $t$

d i p a k a i

$\mathrm{u} n \mathrm{t} \mathrm{u} \mathrm{k}$

membersih

$\mathrm{k}$ a $\mathrm{n}$

material

b e n d a

c a $\mathrm{g}$ a $\mathrm{r}$

b u d a y a

y a $\mathrm{n}$ g

terbuat dari

batu andesit

dan tidak

berrelief (polos).

6. Steam cleaner d a $p$ a $t$ $\mathrm{d}$ i p a k a i $\mathrm{u} \mathrm{n} \mathrm{t} \mathrm{u} \mathrm{k}$ membersih kan batubatu andesit penyusun $C$ a $n$ d i Borobudur dengan batasan tertentu, yaitu dengan jarak pembersihan $25 \mathrm{~cm}$ dan tekanan 100 Bar.

\section{Saran-saran}

1. Pembersihan dengan Steam cleaner harus dilakukan secara selektif dan disarankan hanya dilakukan satu kali dalam setahun untuk lokasi yang sama.

2. Petugas yang menggunakan Steam cleaner, disamping masalah teknis harus mendapat pelatihan dan penjelasan tentang keuntungan dan kerugian membersihkan material benda cagar budaya menggunakan Steam cleaner.

\section{Daftar Pustaka}

Jutono dkk, 1972, Dasar-dasar Mikrobiologi untuk. Perguruan Tinggi, Departemen Mikrobiologi Fakultas Pertanian, Universitas Gadjah Mada, Yogyakarta.

Samidi, 1975, Penelitian Pendabuluan Pemberantasan Lumut pada Batuan Candi Borobudur, Pelita Borobudur Seri B Nomor 7, Departemen Pendidikan dan Kebudayaan, Jakarta.

Sukronedi, S.Si dkk, 2000, Studi Efektivitas Pemberantasan Gulma pada Batuan Secara Fisik, Balai Studi dan Konservasi Borobudur, Magelang.

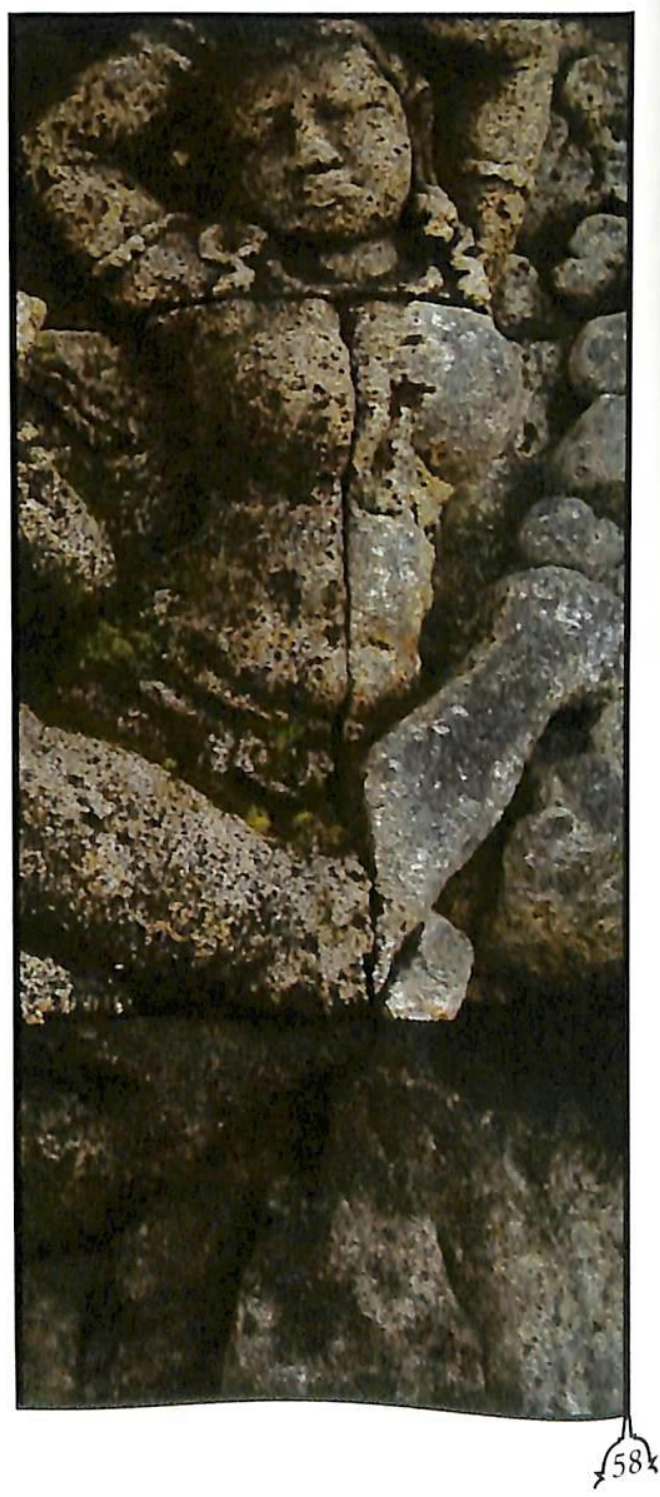

